\title{
The Quest for Resolving Second Language Teaching Dilemma: A Review of the Proposed Solutions during the Last Two Decades
}

\author{
Masoud Mahmoodzadeh \\ Sheikhbahaee University, Isfahan, Iran \\ Email: masoudmahmoodzadeh@yahoo.com
}

\begin{abstract}
This paper intends to address the issue of Second Language Teaching (SLT) Dilemma termed by Danesi (2003). It traces the major scholastic trends to this challenging dilemma in the area of SLT during the past two decades. The study gives a classified overview of two main theoretical trends to resolve this Dilemma. One theoretical trend expresses an ethno-culturally-oriented methodological reaction which focuses on the evolving perspectives on language teaching methods and approaches after the emergence of post-method era. With regard to this trend, the researcher particularly focuses on its two main responses to the SLT Dilemma chronologically listed as: Kumaravadivelu's (1994) "post-method pedagogy" and Larsen-Freeman's (1999) "seven I's". The other theoretical trend expresses a neurolinguisticlly-oriented methodological reaction to the SLT Dilemma which is related to bimodality theory developed by Danesi (2003). The researcher endeavourers to delve into the tenets and principles of these three specific responses to come up with a clear understanding of them which may coherently highlight the two investigated theoretical trends toward the SLT Dilemma accordingly. To this end, the researcher examines the different dimensions of these responses with reference to the following two theoretical questions: (a) why have the pervious methods and approaches failed to tackle the SLT Dilemma?, (b) how can the SLT Dilemma be resolved? In light of such a rationale, the study might be able to compare and elucidate the two investigated theoretical trends and consequently, it might shed more light on the issue of SLT Dilemma from a scholarly outlook.
\end{abstract}

Index Terms - SLT Dilemma, post-method pedagogy, seven I's, bimodality theory

\section{INTRODUCTION}

To date, a plethora of theories on Second Language Teaching (SLT) have generally contributed to the development of second language teaching and learning, all claiming to account for some success achieved in the field of second language teaching and learning. Yet, despite their early relative success from a methodological standpoint, concerns have always been raised about the pedagogical consequences of devising such teaching practices, learning materials, and language syllabuses. For example, several fundamental methods (e.g. Grammar Translation Method, Direct Method, Audio-lingual Method, \& Total Psychical Response) and approaches (e.g. Communicative Language Teaching, \& Task-based Language Teaching) have been proposed to make substantial progress in the domain of second language teaching and learning. But, as such methods or approaches have intended to implement their theories and assumptions in the relevant teaching contexts; the vast majority of them have failed to meet the needs and expectations of their target language learners (Selinker, 1972; Danesi, 2003; Talebinezhad \& Mahmoodzadeh, in press).

In view of such methodological failure, Danesi (2003) raises the notion of SLT Dilemma which claims that despite considerable research on SLA and SLT, language learners rarely achieve high levels of proficiency, irrespective of their background or the employed methodology. To investigate this issue more deeply, three given responses being classified into two distinct theoretical trends in reaction to SLT Dilemma are discussed with reference to the following two theoretical questions: (a) why have the pervious methods and approaches failed to tackle the SLT Dilemma? , (b) how can the SLT Dilemma be resolved?

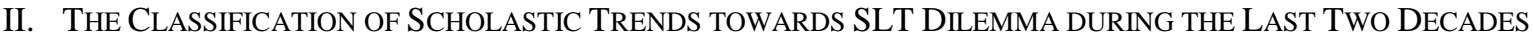

\section{A. The Ethno-culturally-oriented Methodological Reaction to SLT Dilemma.}

In the light of the factors accounting for the phenomenon of SLT Dilemma, ecological and cultural issues can play a pivotal role. In fact, the investigated trend argues that the existence of socio-cultural constraints or barriers may impede the application of the proposed methods and approaches in the teaching environments around the world. For example, $\mathrm{Li}$ (1998) points to the difficulties in South Korea in adopting CLT and attributes the source of the difficulty to the differences between the underlying educational theories of South Korea and Western countries. In Vietnam, Sullivan (1996) conducted an ethnographic research which indicates that views of learning in Vietnam are not always in accordance with CLT. Likewise, Ellis (1994) questions the relevance of CLT in English language teaching by 
Australian teachers in Vietnam. He describes CLT as socially constructed with Western values such as individualism (versus what he calls collectivism in Vietnam) and, as such, not culturally attuned to Asian conditions. However, some researchers have proposed some possible solutions to the SLT Dilemma which are included in this classified approach (Bax, 2003; Bjorning-Gyde \& Doogan, 2004; Bjorning-Gyde, Doogan, \& East, 2008; Breen, 2006; Danesi, 2003; Ellis, 2005; Fenton \& Terasawa, 2006; Jarvis \& Atsilarat, 2004; Johnson, 2006, Kumaravadivelu's, 1994, 2001, 2003a; Larsen-Freeman, 1999). It is worth mentioning that in the last two decades, the significance of the contextual constraints has also been reflected in the area of professional development of language teachers and as a result, some researchers have advocated the move toward socio-contextual perspectives in teacher training (e.g. Bax, 1997; Crandall, 2000; Kumaravadivelu, 2006; Lamie, 2004).

In addition, Kumaravadivelu (2003b) addresses the emergences of colonialism in the prevailing language teaching methods and argues that "the methods used in different parts of the world, however modified they are, still basically adhere to the colonial concept of method"(p. 541). In view of such a colonial phenomenon, Kumaravadivelu maintains that the concept of method seems to be a construct of marginality which can be viewed from its four inter-related dimensions, that is, scholastic, linguistic, cultural, and economic perspectives. To deal with this postcolonial predicament, he proposes a bottom-up processing framework called macrostrategic framework on the basis of the above pedagogical parameters in an attempt to challenge the debilitating effects of method as a means of marginality. The macrostrategic framework consists of both macrostrategies and microstrategies which are derived from theoretical, empirical and experimental insights to second/foreign language learning and teaching. It is a broad guideline based on which teachers are able to generate their own situation-specific or need-based microstrategies and classroom techniques. These macrostrategies include: 1) Maximizing learning opportunities, 2) Minimizing perceptual mismatches, 3) Facilitating negotiated interaction, 4) Promoting learner autonomy, 5) Fostering language awareness, 6) Activating intuitive heuristics, 7) Contextualizing linguistic input, 8) Integrating language skills, 9) Ensure social relevance, 10) Raise cultural consciousness (see Kumaravadivelu, 2003a).

However, more particularly, among the solutions included in this trend, the researcher focuses on two main responses, namely Kumaravadivelu's (1994) post-method pedagogy and Larsen-Freeman's (1999) seven i's which are elaborated below. The researcher attempts to look through the tenets and the underlying assumptions of these theories to find the answers to the two theoretical questions under study.

Kumaravadivelu's "Post-Method Pedagogy" Response.

Why have the pervious methods and approaches have failed to tackle the SLT Dilemma? In response to this question, Kumaravadivelu (1994) discusses that methods and approaches proposed thus far have been considered as the only key to successful teaching. The main reason for this lies in the fact such methods are too dogmatic requiring the teacher's total commitment to their established methodology and overall educational philosophy; therefore, this pedagogical commitment has made it almost impossible to adopt them to different learning and teaching contexts.

As a result, the search for a perfect method which can meet the teachers and learners' needs around the world has led to the accumulation of many teaching methods during the history of language teaching. But, since these methods have been developed and prescribed for use on the basis of the over-generalized methodological knowledge, they have failed to fulfill the teachers and learners' needs and demands to a great extent. Thus, since the pervious methods have been developed based on a set of generalized tenets, they are not context-specific and can not be applied and implemented in all local teaching contexts around the world. In this way, Kumaravadivelu (1994) underemphasizes the pedagogical values associated with the individual methods in the broad context of language teaching and asserts that the method era has come to an end and the search for an alternative method is of no avail.

How can the SLT Dilemma be resolved? The early 1990s witnessed substantial changes and innovations in the domain of language pedagogy. In essence, this was a decade during which the post method era emerged with a focus on how teachers could develop and explore their own teaching through reflective teaching and action research (Richards, 2002). In other words, as discussed by Richards and Lockhart (1994), the emergence of post-method pedagogy led to the revitalization of teaching from the inside rather than by trying to make teachers and teaching to conform to an external model. Kumaravadivelu's (1994) post-method pedagogy was an attempt to resolve the SLT Dilemma. According to this theory, the concept of post-method signifies the search for an alternative to method rather than an alternative method (cited in Kumaravadivelu, 2003b, p. 544). The post methods era has thus led to a focus on the processes of learning and teaching rather than ascribing a central role to methods as the key to successful teaching. As language teaching moved away from a search for the perfect method, attention shifted to how teachers could develop and explore their own teaching through reflective teaching and action research (Kumaravadivelu, 2001). Thus, it seems that post method pedagogy seeks to empower practicing teachers in an attempt to develop an appropriate pedagogy based on their local knowledge and local understanding" (Kumaravadivelu, 2003b). Kumaravadivelu (2001) discusses that a post method pedagogy must "a) facilitate the advancement of a context-sensitive language education based on a true understanding of local linguistic, sociocultural, and political particularities; (b) rupture the reified role relationship between theorists and practitioners by enabling teachers to construct their own theory of practice; and (c) also tap the sociopolitical consciousness that participants bring with them " (p. 537).

According to Kumaravadivelu (2003b), post method pedagogy consists of a three-dimensional system including three pedagogical parameters of particularity, practicality, and possibility. These parameters "interact with each other in a 
synergic relationship where the whole is greater than the sum of its parts" (p. 545). The first and foremost, any post method pedagogy has to be pedagogy of particularity. That is to say, language pedagogy, to be relevant, "must be sensitive to a particular group of teachers teaching a particular group of learners pursuing a particular set of goals within a particular institutional context embedded in a particular sociocultural milieu" (Kumaravadivelu, 2001, p. 538). To phrase in another word, such a pedagogy is "responsive to and responsible for local individual, institutional, social, and cultural contexts in which learning and teaching take place" (Kumaravadivelu, 2003b, p. 544). In short, pedagogy of practicality aims for a teacher-generated theory of practice. This assertion is premised on a rather simple and straightforward proposition: No theory of practice can be useful and usable unless it is generated through practice (Kumaravadivelu, 2001). And, the parameter of possibility "is derived mainly from Freirean critical pedagogy that seeks to empower classroom participants so that they can critically reflect on the social and historical conditions contributing to create the cultural forms and interested knowledge they encounter in their lives" (Kumaravadivelu, 2003b, p. 544).

However, in terms of the critiques of the premises of the post-method paradigm, Tajeddin (2005) argues that "while being a consequence of the general trend of paradigm shift, the post method paradigm is founded on a number of premises prevalent in the method era despite its repeated disenchanted with the concept of method" (p. 1). According to Tajeddin, in spite of the attempts to disenchant the realm of language teaching with the very word method (Kumaravadivelu, 1994, 2001, 2003a), on the one hand, the applications of post-method paradigm have filed to permeate the area of syllabus design, materials development, language testing, and classroom practice while on the other hand, methods still have theoretically and practically outlived the so-called method era. Therefore, according to Tajeddin, the post-method framework has not been disenchanted with the category of method and it stills seems to fall within the category of method by its nature. The other securitized response to the SLT Dilemma included in this theoretical trend relates to Larsen-Freeman's (1999) "seven I's" which is briefly elaborated below.

Larsen-Freeman's "Seven I's" Response.

Why have the pervious methods and approaches failed to tackle the SLT Dilemma? Larsen-Freeman (1999) discusses that a number of scholars in our field have criticized language teaching methods during the last two decades. Some have noted that the search for the best method is ill-advised (e.g., Bartolome, 1994) claiming that there can be no one best method. But there has been an additional concern registered which is worth of attention. Larsen-Freeman questions the assumption that a method that is suitable in one part of the world is appropriate for all parts of the world. In view of this methodological crisis, some researchers (Breen, 2006; Butler, 2005; Canh, 1999; Chowdhury, 2003; Ellis, 1994; Hu, 2002; Kumaravadivelu, 2006; Li, 1998; Nishino, 2008; Pennycook, 1989; Savignon \& Wang, 2003; Stapleton, 1995; Wu \& Fang, 2002) have also offered some similar supporting evidence for CLT approaches. That is, they have demonstrated that as Larsen-Freeman (1999) discusses, some methodological challenges in this regard indicating that although CLT is perceived as progressive and modern in some parts of the world, it is not seen as an appropriate way to teach languages everywhere, since many of its underpinning values conflict with those of other cultures. Thus, teachers are obliged to abandon the use of the method in question, even though here there is nothing wrong with the application or actual usefulness of the method but the problem is that this methodology does not fit these teaching contexts.

Likewise, Larsen-Freeman (1999) underscores the intrinsic value of the method itself and disapproves of the emergence of Kumaravadivelu's (1994) post-method pedagogy in the area of second language teaching. Larsen-Freeman argues that it seems a pity that post-method teaching is the final response to the SLT Dilemma. For after all, much good can come from working with language teaching methods. However, in attempting to be culturally appropriate, it is not intended to contribute to the de-skilling of teachers by deciding a priori that a method is inappropriate to a given context. Indeed, she maintains that "assuming that teachers are helpless victims of ideological imposition and disregarding their agency in the teaching/learning process seems just as much an affront as assuming that new methodologies are superior to traditional ones". Teachers and teacher educators should not be blinded by the criticisms of methods and thus fail to see their invaluable contribution to teacher education and continuing development (p. 26).

Larsen-Freeman (1999) discusses that the main reason for this methodological failure lies in the fact the proposed methods have been imposed on teachers by others and thus, they are not going to be shaped by teaching a teacher's own understanding, beliefs, style, and level of experience while being implemented in the relevant teaching contexts. To put it in another word, the current methods are falsely assumed to be fully intact formulaic packages for practice in the classroom.

How can the SLT Dilemma be resolved? In reply to this question, Larsen-Freeman (1999) discusses that the key to resolve the SLT Dilemma is moving beyond ideology to inquiry, a way which can avoid the inappropriate uses of methods, while benefiting from them at the same time. To elaborate on her proposal, she introduced the notion of seven "I's" - moving from Ideology to Inquiry while challenging notions of Inclusive generalizations, Imposition leading to Implementation, Intactness, and Immutability. Some tenets of the seven "I's" are briefly discussed in the following: first of all, it must be explicitly acknowledged that language teaching methods do reflect ideological positions. Methods are not just empty vehicles delivering language content. By inquiring into their practice via interacting with other ideologies, it helps keep teachers' teaching alive and prevent it from becoming stale and overly routinized (Prabhu, 1990). Further, it is a leap of logic to assert that because methodologies rest upon certain values, it therefore follows that they are 
automatically inappropriate for certain cultural contexts. In teaching, of course, we are not engaged with whole cultures, but with individuals within a culture. We need to reconcile ideas about the influence of culture with recognition of individual differences (Larsen-Freeman, 1999).

As Littlewood (1999) has observed such generalizations as all Vietnamese or Japanese value collectivizing over individualizing and collaboration over competition are false. Educators can treat such tendencies as starting points or hypotheses about students' behavior, but such inclusive statements are clearly overgeneralizations. Larsen-Freeman (1999) discusses that a method is a coherent set of links between thoughts (or beliefs) and actions in language teaching. Methods are coherent in the sense that there should be some theoretical or philosophical compatibility among the various thought-action links. Of course, a teacher may also simply borrow the techniques of a method, without its accompanying value. Learning to teach is a developmental process. Skilled teachers do not emerge from teaching preparation programs ready to implement a particular method. They must not only develop their thoughts about teaching, but also their actions or techniques. According to Larsen-Freeman (1999),

"Methods are not immutable in practice. As teachers gain experience, they come to understand a particular method differently. Thus, methods are not something superimposed on teaching. They are instantiated differently, not only due to contextual differences, but also due to the teachers' stage of development. In order for this matter to be realized, the ideology underlying a method must be acknowledged, but so must the spurious views on methodology called the "i" myths: the myths of inclusive generalization, the myth that imposing a method will lead to its implementation, and the false assumptions that methods are fully intact and immutable packages. Decisions about appropriate methodology should be made by local educators, taking their students' needs into account" (pp. 28-29).

\section{B. The Neurolinguistically-based Methodological Reaction to SLT Dilemma.}

During the last decade, pedagogical applications of neurolinguistic studies have permeated in the domain of SLA and have strengthened the body of knowledge of this field accordingly. In light of their significant contribution to SLA, seemingly the advent of Danesi's (1986) bimodality theory has initiated a neurolinguistically-based methodological reaction to view the SLT Dilemma from a vantage point. Nonetheless, one interesting fact in this regard is that this theory being amended by Danesi (2003) may be considered as the only methodological endeavourer to approach the SLT Dilemma from a neurolinguistic aspect during the last decade. In this sense, a few scholars, however, have addressed the prevailing neurolinguistic gap in the literature of the second language studies (e.g. Kim-Rivera, 1998). To meet the aims of the study, the researcher here attempts to securitize the principles and the underlying assumptions of this theory to find the answer to the following theoretical questions.

Danesi's "Bimodality Theory" Response.

Why have the pervious methods and approaches failed to tackle the SLT Dilemma? According to Danesi (2003), bimodality theory, one of the recent views on SLT which radically ushered in a new era of research in second language learning and teaching, suggests that the reason that so many methods and approaches in SLT have relatively tended to fail lies in the fact that all of them were in part unimodal, that is, focusing on only one of the two hemispheres of the brain. For example, on the one hand, the methods such as Grammar Translation Method or Audio-lingual Method focused only on the left hemisphere (L-Mode) while, on the other hand, the Communicative, Humanistic, and Neurolinguistic methods and approaches overemphasized the right hemisphere (R-Mode) to the detriment of the L-Mode.

As Danesi (1988) discusses, at the end of the 19th century, the designation of the left hemisphere as major or dominant and the right as weak or minor caused teaching methods to be unimodal, that is, to concentrate on the structural form of language. The pedagogical implications of this signified a tendency to neglect those features associated with the right hemisphere (usually the creative/artistic qualities). Further research continued to strengthen the views that the left hemisphere was programmed for form and the right controlled content, in that it deciphered new stimuli in an efficient manner.. Therefore, the methods that pursued grammatical linguistic competence only exercised the left hemisphere actively (cited in Antenos-Conforti, 2001, pp. 30-31).

Needless to say, although the techniques utilized in inductivist and deductivist methods focused on developing L-Mode control of second language, it should be noted that some of the techniques used in the inductivist method- e.g. the use of the situational practice, the incorporation of visual stimuli, the contextualization of practice routines, etc.-did have an R-Mode focus. And, it might explain why they have survived to this day as effective techniques on their own (Danesi, 2003).

However, on the other hand, Communicative, Humanistic, Neurolinguistic methods and approaches were designed with an opposite unimodal bias. They typically overemphasized and utilized R-Mode functions to the detriment L-Mode functions. This is why they always generated much interest at first, but seldom produced high level of proficiency at the end of a course of study. Moreover, it should be noted that no method or approach has ever been designed intentionally to be unimodal. It is more accurate to think of SLT practices generally as placeable on a continuum with two extreme L-Mode and R-Mode endpoints (i.e. GTM \& Silent Way methods, respectively) at which bimodality theory suggests the mid-point of this continuum as the most appropriate for SLT practice (Danesi, 2003, p. 49).

How can the SLT Dilemma be resolved? In reaction to this dilemma, Danesi (2003) discusses that bimodality theory is an attempt to provide neurolinguisic foundation for language instruction in the classroom. Its underlying assumption is that there is a natural flow of information from the right to the left hemisphere of the brain during language learning. 
In fact, bimodality theory's response to SLT Dilemma which is mainly based on the findings of the neurolinguistic studies suggests that the optimal solution to the current dilemma lies in the systematic utilization of both hemispheres of the brain during the process of language learning. In effect, as Danesi states, any instructional system that privileges only one of the two modes of brain is bound to fail sooner or later because such a system has been unimodally developed. Nevertheless, as Danesi and Mollica (1988) note, bimodality does not dictate any specific instructional routine or style; it can be adapted into any textbook, regardless of emphasis. Thus, this theory is compatible with the notion of proficiency in that it is a multifaceted concept that adapts to all methodologies, approaches, and techniques.

It is worth mentioning that the principles and techniques of bimodality theory have been developed and extended during the last two decades. In essence, Danesi (2003) proposes the most recent pedagogical implications of bimodality theory through a set of pedagogical principles and techniques. These principles and techniques can assist language teachers to improve their teaching. Also, they can inform syllabus designers and material developers of the recent findings of neurolinguistic studies so that they are able to design more efficient ELT materials for EFL/ESL learners. However, they are four pedagogical principles which are derived from the recent relevant brain research corresponding directly to the application of bimodality theory in SLT. Danesi introduced these principles as follows: (1) the modal flow principle; (2) the modal focusing principle; (3) the contextualization; (4) the conceptualization principle. The consolidation of these principles would effectively enhance the learning of the language, as they integrate both structure and communication, and thus educate both hemispheres at the same time. The summery of these informative principles are concisely explained below.

By definition, the modal flow principle (also known as modal directionality principle) "signifies that at first the experiential plane is activated (the R-mode), then new input flows to the analytical (the L-mode), as was generally the case with the inductive principle"(Mollica \& Danesi 1998, p. 209). However, the principle of modal directionality should be utilized only with new input, so that foreign language learners may experience a new structure or concept before shifting to the formal explanation as to why it is so (Antenos-Conforti, 2001).Young and Danesi (2001) discuss that during the initial learning stages, students need to assimilate new input through observation, induction, role-playing, simulation, oral tasks, and various kinds of interactive activities. But formal explanations, drills, and other L-Mode procedures must also follow these stages, since we have found that control of structure will not emerge spontaneously. Danesi (2003) divided the neurological basis of the brain during the process of learning a new language into three neurolinguistic stages and then identified the general procedures being utilized in any teaching context based on the modal flow principle. These stages as well as their characteristics are discussed below:

During an R-Mode Stage: Classroom activities should be student-centered and involve students and teacher in a complementary fashion. Novel input should be structured in ways that activate sensory, experiential, inductive forms of learning (dialogues, questioning strategies, simulations, etc.). And, the students' inductive and exploratory tendencies should be encouraged to operate freely when introducing new information.

During an L-Mode Stage: The focus here shifts to the teacher. The teacher should explain the structural and conceptual features of the new materials clearly using deductive and inductive techniques as warranted by the situation. And focusing on some problematic aspect of the subject being taught is to be encouraged if a student appears to have difficulty grasping it or using it with appropriate comparison to the NL and with suitable exercise materials.

During an Intermodal Stage: The learner should be allowed to employ the new materials to carry out real- life verbal tasks, but only after he/she shows the ability or willingness to do so. Teaching new things or discussing matters of form and structure during this stage should be avoided. Students should be allowed to find solutions to problems of communication on their own. Role-playing and work in pairs or groups is advisable for most students, although some may not wish to participate. The latter can be assigned other kinds of creative tasks (e.g. writing).

Modal focusing principle is required at points in the learning process when, for instance, a learner appears to need help in overcoming some error pattern that has become an obstacle to learning. L-Mode focusing allows the learners an opportunity to focus on formal matters for accuracy and control while R-mode focusing allows the learners to engage in matters of understanding and conceptualization (Danesi, 2003). As Mollica and Danesi (1998) mentioned, "the modal focusing stresses the fact that, at some time during the learning process, students may need to concentrate on one mode or the other to digest new data, reinforce acquired structures or vocabulary, or simply think of what to say" (p. 210).

In terms of contextualization principle, Danesi (2003) argues that memorizing or pronouncing words in isolation, rehearsing speech formulas, or even practicing grammar without reference to some situation that typically entails them, rarely leads to learning. The reason is that language derives its meaning (usage) primarily from the context in which it is involved (i.e. its use). So, without sufficient context, it is unlikely that the brain can assimilate new input in any mnemonically functional way. Danesi (2003) also maintains that during an R-Mode Stage, the new material must contain references to cultural concepts in order for the brain to detect the appropriate meaning potential of the new structures whereas, during an L-Mode Stage, the practice and rehearsal of the new structures is greatly enhanced if practical or conceptual information is provided.

Concerning the conceptualization principle, Danesi (2003) discusses that a common observation of teachers is that students often produce L2 messages which are semantically anomalous when they attempt to speak or write spontaneously without some form of guidance. Danesi identifies the source of such anomaly in the unconscious tendency of learners to put together L2 messages on the basis of L1 concepts. Thus, the language teacher must ensure 
that the two systems- the linguistic and the conceptual- are interrelated during all aspects and stages of instruction and practice. Moreover, "in terms of dealing with incoming conceptual structures, the conceptualization principle can manifest itself in one of these three ways:(1) isomorphic (2) overlapping (3) differentiated"(p. 66). As Danesi (1993) suggests the student learning a L2 must thus learn about the life of the language through his/her understanding of concept boundaries, metaphorical usage, proverbs, and conceptual domains. Included in this domain of language are also al1 the nonverbal language of a target culture such as gestures, tone, social interactions and register.

Moreover, as discussed by Danesi (2003), after the proposal of bimodality theory, a number of second language teachers and researchers, especially in Italy and North America began assessing the implications of this theory critically (Curro, 1995; Lombardo, 1988; Nuessel \& Cicogna, 1992; Pallotta, 1993). In addition, with respect to the application of this theory, Talebinezhad and Mahmoodzadeh (in press) has recently conducted a study investigating the pedagogical applications of bimodality theory in a selection of both internationally-developed and locally-developed ELT textbooks used widely in Iran. In the end, the results of the study revealed that pedagogical techniques and principles of bimodality theory appear to be significantly more applied in the design of the internationally-developed ELT textbooks than the locally-developed ones. The study also suggested that perhaps one of the main reasons for the inefficiency of the locally-developed ELT textbooks used in Iran was the marginality of the pedagogical techniques and principles of bimodality theory in them and that the textbooks need to be modified in order to be more in line with the pedagogical objectives of bimodality theory.

However, since the arrival of the tenets of bimodality theory, some researchers have cast doubt on the application of this theory. For example, Kim-Rivera (1998) argues that there are some issues concerning Danesi's bimodality theory. One of these issues is that few empirical studies have been carried out to support this theory (e.g. Danesi \& Mollica, 1988; Danesi, 1988) and only when a consistent pattern of significant results is available can bimodality be considered worthy as a theoretical basis for instructional practice. According to Kim-Rivera, another issue is that Danesi's bimodality theory has been the only concrete proposal for second language teaching from the perspective of neuroscience. Accordingly, there have been few arguments for or against it from SLA researchers and the validity of this theory requires additional research and the support of future neurolinguistic findings.

\section{DISCUSSION}

In the current study, the overview of the classified theoretical trends in reaction to SLT Dilemma reveals that, on the one hand, seemingly the appeal to resolve this dilemma from ethno-cultural perspectives has been considerably documented by many researchers during the last two decades, whereas the attempt to enrich our knowledge of second language learning and teaching on the basis of the relevant neurological findings still has not been welcomed by SLA researchers to a great extent. To my knowledge, during the last decade, Danesi's (2003) bimodality theory seems to be the only worthwhile example of the neurolinguistically-oriented methodological reaction which has aimed to crystallize the findings of the recent neurolinguistic studies into a pedagogically systematic scheme set forth for the ELT practitioners. However, it is worth noting that, unlike the previously well-documented neurrolinguistically-based theories such as Critical Period Hypothesis (CPU) and Parallel Distributed Processing (PDP), bimodality theory perhaps suffers from a clear-cut research gap. In effect, by no means it has been the focus of SLA researchers during the last decade, even though it has not put forward fewer practical guidelines and implications for language teaching practices than the two afore-mentioned theories.

On the other hand, seemingly the path which has been gone through by the SLA researchers in the trend of ethno-culturally-oriented methodological reaction to the dilemma in question is significantly more subject to the phenomenon of contextual variations and thus, this trend might not find an optimal solution to all endless contextual and cultural teaching constrains. In contrast, the neurolinguistically-based methodological reaction to SLT Dilemma seems to favor some systematic frameworks which are not context-specific and perhaps are unlikely to be affected by the above-mentioned ethno-cultural impediments. In fact, the methodological foundations of the theories in this trend (e.g. bimodality theory) appear to make them fit various socio-cultural teaching environments. In this way, the effects of socio-cultural variations can probably be avoided to a great extent accordingly.

However, it should be noted that one can not assume Danesi's (2003) bimodality theory as an optimal response to SLT Dilemma, since as was mentioned earlier, only a few studies have been conducted so far exploring its practical applicability among EFL/ESL language learners in different teaching environments (e.g. Curro, 1995; Danesi \& Mollica, 1988; Lombardo, 1988; Nuessel \& Cicogna, 1992; Pallotta, 1993). Hence, this theory entails further research studies with sufficient corroborating results to gain more pedagogical credit in the future. In a nutshell, if such a scholarly phenomenon occurs, then this theory might have the potential status of a new paradigm and might cause a paradigm shift in the theoretical trends towards the issues of SLT Dilemma. Since as Kuhn (1970) discusses, a new paradigm is formed in science when a revolution occurs in thinking of the shatter pervious ways of approaching or viewing a discipline.

\section{CONCLUSION}


This paper has attempted to demonstrate how the SLT Dilemma has been treated by the researchers in the area of SLT during the last two decades. After looking over the classified trends under study, the researcher suggests similar points for SLT Dilemma as Ellis (2005) suggests for a possible dilemma in SLA. That is, perhaps SLT like SLA is still in its infancy, since the search and theory still do not afford a uniform account of how instruction can best facilitate language learning; therefore, it seems that the proposed theatrical trends towards resolving the issue of SLT Dilemma are still open to debate unless there is a consistent and close alignment between their advocated assumptions and the corollaries of their corresponding studies.

\section{REFERENCES}

[1] Antenos-Conforti, E. (2001). The teaching of Elementary Italian as a Second Language in Canadian Universities: Methodologies, Curricula and Future Considerations. Unpublished Doctorial Dissertation, University of Toronto, Canada.

[2] Bartolome, L. (1994). Beyond the methods fetish: Toward a humanizing pedagogy. Harvard Educational Review, 64(2), 173-194.

[3] Bax, S. (1997). Roles for a teacher trainer in context-sensitive teacher education. ELT Journal, 51(3), $232-241$.

[4] Bax, S. (2003). The end of CLT: A context approach to language teaching. ELT Journal, 57(3), $278-287$.

[5] Bjorning-Gyde, M., \& Doogan, F. (2004, May). The fusion model: Blending the West and the East in the contemporary language classroom in China. Paper presented at the Second Annual Conference of IATEFL China, Tonghua, PRC. Retrieved November 23, 2007, from http://www.trinitycollege.co.uk/resource/?id=2387

[6] Bjorning-Gyde, M., Doogan, F., \& East, M. (2008). Towards a fusion model for the teaching and learning of English in a Chinese context. In M. Wallace \& L. Dunn (Eds.), Teaching in transnational higher education: Enhancing learning for offshore international students (pp. 77-87). New York: Routledge.

[7] Breen, P. (2006). The education of language teachers in East Asia. Asian EFL Journal, 4(4). Retrieved May 13, 2007, from http://www.asian-efl-journal.com/pta_july_06_pb.php

[8] Butler, Y. G. (2005). Comparative perspectives towards communicative activities among elementary school teachers in South Korea, Japan and Taiwan. Language Teaching Research, 9(4), 423-446.

[9] Canh, L. (1999, October). Language and Vietnamese pedagogical contexts. Paper presented at the Fourth International Conference on Language and Development, Hanoi. Retrieved September 9, 2006, from http://www.languages.ait.ac.th/hanoi_proceedings/canh.htm

[10] Chowdhury, R. (2003). International TESOL training and EFL contexts: The cultural disillusionment factor. Australian Journal of Education, 47(3), 283-302.

[11] Crandall, J. (2000). Language teacher education. Annual Review of Applied Linguistics, 20, 34-55.

[12] Curro, G. (1995). A Survey of Neurolinguistic Research and Its Implications for Second Language Teaching. Unpublished Doctorial Dissertation. James Cook University, North Queensland.

[13] Danesi, M. (1986). Research on the Brain's Hemispheric Functions: Implications for Second Language Pedagogy. Lenguas Modernas, 13, 99-113.

[14] Danesi, M. (1988). Studies in Heritage Language Learning and Teaching. Toronto: Centro Canadese Scuola e Cultura Italiana.

[15] Danesi, M. (2003). Second Language Teaching: A View from the Right Side of the Brain. The Netherlands: Kluwer Academic Publishers.

[16] Danesi, M. (1993). Vico, Metaphor, and the Origin of Language. Bloomington: Indiana University Press.

[17] Danesi, M. and Mollica, A. (1988). From Right to Left: A "Bimodal" Perspective of Language Teaching. Canadian Modern Language Review, 45(1), 76-86.

[18] Ellis, G. (1994). How culturally appropriate is the communicative approach? ELT Journal, 50(3), 213-218.

[19] Ellis, R. (2005). Instructed second language acquisition: A literature review. Wellington, New Zealand: New Zealand Ministry of Education. Retrieved December 11, 2008, from http://www.educationcounts.govt.nz/data/assets/pdf_file/0008/6983/instructed-second-language.pdf

[20] Fenton, A. L., \& Terasawa, Y. (2006). Paradigm lost? A belated reply to Jarvis and Atsilarat from Japan. Asian EFL Journal, 4(4), 219-237. Retrieved December 15, 2007, from http://www.asian-efl-journal.com/March_06_af\&yt.php

[21] Hu, G. (2002). Potential cultural resistance to pedagogical imports: The case of communicative language teaching in China. Language, Culture and Curriculum, 15(2), 93-105.

[22] Jarvis, H., \& Atsilarat, S. (2004). Shifting paradigms: From a communicative to a context-based approach. Asian EFL Journal, 6(4). Retrieved December 14, 2007, from http://www.asian-efl-journal.com/december_04_HJ\&SA.php

[23] Johnson, K. (2006). The sociocultural turn and its challenges for second language teacher education. TESOL Quarterly, 40(1), $235-252$.

[24] Kim-Rivera, E. G. (1998). Neurolinguistic Applications to SLA Classroom Instruction: A Review of the Issues with a Focus on Danesi's Bimodality. Texas Papers in Foreign Language Education, 3(2), 91-103.

[25] Kumaravadivelu, B. (1994). The post method condition: (e)merging strategies for second/foreign language teaching. TESOL Quarterly, 28(1) 27-48.

[26] Kuhn, T. (1970). The Structure of Scientific Revolution. Chicago: University of Chicago Press.

[27] Kumaravadivelu, B. (2001). Towards a postmethod pedagogy. TESOL Quarterly, 35(4), 537-559.

[28] Kumaravadivelu, B. (2003a). Beyond methods: Macrostrategies for language teaching. New Haven, CT: Yale University Press.

[29] Kumaravadivelu, B. (2003b). Forum Critical Language Pedagogy: A post-method perspective on English Language teaching, World Englishes, 22(4), 539-550.

[30] Kumaravadivelu, B. (2006). TESOL methods: Changing tracks, challenging trends. TESOL Quarterly, 40(1), 59-81.

[31] Lamie, J. M. (2004). Presenting a model of change. Language Teaching Research, 8(2), 115-142. 
[32] Larsen-Freeman, D. (1999, October). On the appropriateness of language teaching methods in language and development. Paper presented at the Fourth International Conference on Language and Development, Hanoi. Retrieved October 3, 2010, from http://www.languages.ait.ac.th/hanoi_proceedings/larsen-freeman.htm.

[33] Li, D. (1998). "It's always more difficult than you plan and imagine": Teachers' perceived difficulties in introducing the communicative approach in South Korea. TESOL Quarterly, 32(4), 677-708.

[34] Littlewood, W. (1999). Defining and developing autonomy in East Asian contexts. Applied Linguistics, 20(1), 71-94.

[35] Lombardo, L. (1988). Helping Learners to Establish Criteria in an L2: Promoting Learner Autonomy in the Foreign Language Classroom. In G. Cecioni (Ed.), Proceedings of the Symposium on Autonomy in Foreign Language Learning, (pp. 70-79). Firenze: Centro Linguistico di Ateneo.

[36] Mollica, A. \& Danesi, M. (1998). The Foray into the Neurosciences: Have We Learned Anything Useful? .In A. Mollica (Ed.), Teaching and Learning Languages (pp. 201-215), WeIland, ON (Canada): Éditions Soleil.

[37] Nishino, T. (2008). Japanese secondary school teachers' beliefs and practices regarding communicative language teaching: An exploratory survey. JALT Journal, 30(1), 27-50.

[38] Nuessel, F., \& Cicogna, C. (1992). Pedagogical Applications of the Bimodal Model of Learning through Visual and Auditory Stimuli. Romance Languages Annual, 11(3), 289-292.

[39] Pallotta, L. L. (1993). The "Bimodal" Aspect of Proficiency-Oriented Instruction. Foreign Language Annals, 26(4), $429-434$.

[40] Pennycook, A. (1989). The concept of method, interested knowledge, and the politics of language teaching. TESOL Quarterly, 23(4), 591-615.

[41] Prahbu, N. S. (1990). There is no best method - Why? TESOL Quarterly, 24(2), 161-176.

[42] Richards, J. C. (2002). 30 Years of TEFL/TESL: A personal Reflection. RELC Journal, 33(2), 1-35.

[43] Richards, J. C. \& Lockhart, C. (1994). Reflective Teaching in Second Language Classrooms. New York: Cambridge University Press.

[44] Savignon, S., \& Wang, C. (2003). Communicative language teaching in EFL contexts: Learner attitudes and perceptions. International Review of Applied Linguistics in Language Teaching, 41(3), 223-249.

[45] Selinker, L. (1972). Interlanguage. International Review of Applied Linguistics, 10, 209-231.

[46] Stapleton, P. (1995). The role of Confucianism in Japanese education. The Language Teacher, 19(4), 13-16.

[47] Sullivan, P. N. (1996). English language teaching in Vietnam: An appropriation of communicative methodologies. Unpublished Doctoral Dissertation, University of California, Berkeley.

[48] Tajeddin, Z. (2005). A critique of the inception and premises of the Postmethod Paradigm. ILI Language Teaching Journal, $1(1), 1-14$.

[49] Talebinezhad, M. A. \& Mahmoodzadeh, M. (in press). Re-evaluation of Internationally and Locally-Developed ELT Materials in Iran: A Bimodal Approach to Material Development. Journal of Language Teaching and Research.

[50] Wu, X., \& Fang, L. (2002). Teaching communicative English in China: A case study of the gap between teachers' views and practice. Asian Journal of English Language Teaching, 12, 143-162.

[51] Young, B. A. \& Danesi, M. (2001). Studying How the Brain Learns: Are There Any Useful Implications for Instruction? Retrieved July 4, 2010, from http://www.arrowsmithschool.org/howbrainlearns.htm

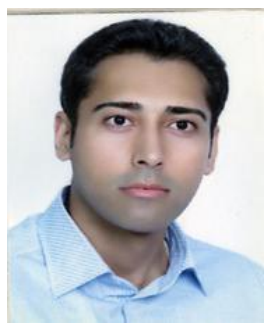

Masoud Mahmoodzadeh was born in Mashhad, Iran, 1985. He received his B.A. degree in English Language Translation from Imam Reza University (pbuh), Mashhad, Iran, in 2008. He earned his M.A. degree in TEFL at Sheikhbahaee University, Isfahan, 2011. He is, at the moment, an EFL teacher and supervisor working in the English language centers in Mashhad, Iran. He has been teaching English to Iranian EFL learners in several language institutes since 2004. He has also taught General English courses at Sheikhbahaee University, Isfahan.. He is also a co-author of the paper "Re-evaluation of Internationally and Locally-Developed ELT Materials in Iran: A Bimodal Approach to Material Development" which will be published soon in the forthcoming publications of the Journal of Language Teaching and Research, November 2011(Paper ID: JLTR11042001).His main areas of interests include second language acquisition and curriculum planning/evaluation. 